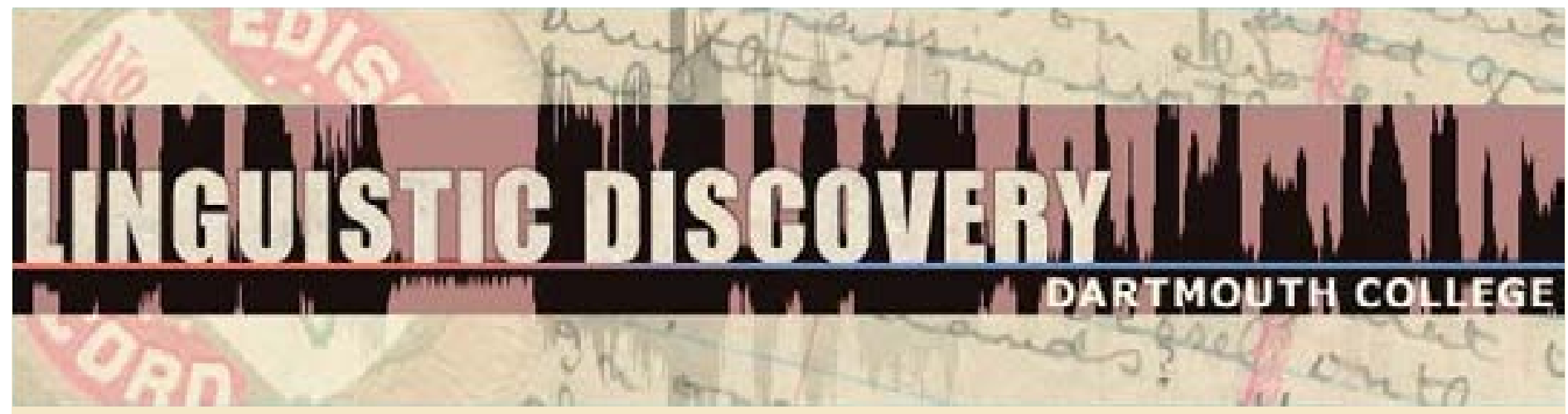

\begin{tabular}{|l|}
\hline Volume 8 \\
Issue 1 \\
2010 \\
\hline
\end{tabular}

\title{
Commentary on Malchukov - Optimizing Classical Maps
}

Heiko Narrog

Tohoku University

doi: $10.1349 / P S 1.1537-0852 . A .372$

url: http://journals.dartmouth.edu/cgi-bin/WebObjects/ Journals.woa/1/xmlpage/1/article/372

\section{Linguistic Discovery}

Published by the Dartmouth College Library Copyright to this article is held by the authors. ISSN 1537-0852 linguistic-discovery.dartmouth.edu 


\title{
Optimizing Classical Maps
}

\section{Comment on 'Analyzing Semantic Maps: A Multifactorial Approach' by Andrej L. Malchukov (2010)}

\author{
Heiko Narrog \\ Tohoku University
}

To state my bias as a reader and commentator in the beginning, I should say that the approach taken by Malchukov is very close to my own approach to semantic maps, so I am naturally sympathetic towards his contribution. However, I believe that the breadth of the issues, the wealth of data and the depth of consideration presented therein make still it a particularly outstanding paper even if one might not likewise sympathize with the author's stance. As I basically share this stance, my comment will mainly serve to recapitulate his argumentation, and fill in possible gaps where this seems appropriate.

Malchukov starts out by contrasting the 'traditional' or 'classical' approach to semantic maps with the 'alternative' approach, that which we may also call 'statistical maps'. He makes clear that both approaches have advantages and drawbacks. According to Malchukov, the most significant disadvantages of classical maps are

a. their incapability of representing frequency,

b. the spread of 'vacuous' maps if minority patterns are taken into account on a par with majority patterns.

From a certain perspective, one may view (b) as a side effect of (a), as it also pertains to frequency. Another factor that could be added here, and which is also related to frequency, at least partially, is that classical maps are (c) not good at representing degrees of similarity in general because of the limitations in arranging category labels in a two-dimensional space. One result of such limitation is that two meanings or functions placed close to each other may not in fact be connected by a line and may stand in a relationship of direct meaning extension, while "related" meanings might have to be placed further apart. In other words, the distance between meanings or functions is not always indicative of their similarity or relatedness. In Malchukov's view, however, representation of similarity is not the foremost task of a semantic map anyway (cf. section 7). As for their advantages, according to Malchukov, classical maps can

d. capture semantic connections between individual categories,

e. represent a diachronic dimension (see also Narrog 2010, and van der Auwera 2008), and

f. feed directly into semantic analysis.

That statistical maps lack these advantages is their major drawback, while, conversely, their strength lies in the representation of frequencies, thus reversing (a) and (c) in particular.

Malchukov's main goal in this paper is to advance on the difficulty which problem (b) presents for classical maps, and thereby further establish classical maps as an effective tool in semantic analysis. The task is to avoid inclusion of minority patterns which are not due to semantic similarity and thus must be considered as noise when constructing a map. One could go a step further and claim that the process described by Malchukov could be profitably applied to the construction of statistically plotted maps as well, provided that these maps are not constructed mechanically on the basis of a set of data, but the data (e.g. translation data such as those used by Wälchli 2010) are first analyzed by hand. After all, (b), depending on the point of 
view, may be perceived as a problem common to the statistically-driven approach as well. Malchukov claims that the following types of "noise" can be identified (the labeling I attach to these types is not identical to Malchukov's but reflects my own understanding).

1. markedness effects, specifically neutralization of semantic/functional contrasts in the marked category of a paradigm (section 2)

2. zero marking (section 3 )

3. polysemies which should not occur in natural language data for reasons of distinguishability, but occasionally do occur due to coincidences in diachronic development (section 4)

4. unusual polysemies of lexical items involved in grammatical patterns (section 5)

5. wide-ranging polysemies of lexical verbs when they begin to grammaticalize as serial verbs (section 6.1)

6. polysemies due to reanalysis rather than meaning extension (section 6.2)

7. lack of linking meaning/function due to gram replacement (section 6.3)

As far as I know, Malchukov is the first to present all these interfering factors together in one paper. "Noise type" (7) was already brought up by Haspelmath (2003:236), but I was unaware of many others, and I assume other readers were too, at least in this context.

Empirically speaking (as is obvious from Malchukov's description), these problems are hardly likely to occur all together in a single area of grammar on one map, but depend on the type of categories involved. If a map of grammatical categories needs to include the features of lexical items (problems 4 and 5), it is natural that idiosyncratic features of the lexical items should be excluded from the grammatical map to the extent possible. Labeling factors (1), (2), (6), and (7) as 'interfering' should also be uncontroversial. Especially (7) is already well established, and it is highly problematic to speak of a polysemy or meaning extension of zero marking (2). The least obvious "noise" in my view is (3), namely, those polysemies that should not occur for reasons of distinguishability but nevertheless do, in some rare cases. These cases, as presented by Malchukov, are the quirky product of regular semantic extension, and thus fulfill the criterion for being represented in a semantic map. Semantic maps should represent empirically attested meaning extensions as fully as possible, even if they turn out to be inconvenient for the theory and result in inelegant hypotheses on semantic similarity and meaning extension. This is a point to which Malchukov would certainly also agree. I believe that, for classical maps, one possibility to represent such quirky or rare connections would be to choose different types of lines.

One type of noise which is fairly well-known but not mentioned by Malchukov is case syncretism due to phonological changes (primarily phonological reduction of the desinences, cf. e.g. Baerman 2009, section 14.4). Here, the motivation for formal identity is also non-semantic, and excluding the resultant polysemies from semantic maps seems to be sensible. A more general question related to this "noise" might be to what extent inflectional paradigms with phonologically heavily reduced desinences can still provide a reliable base for a study that is grounded in iconicity between (phonological) form and meaning.

\section{References}

Baerman, Matthew. 2009. Case syncretism. The Oxford handbook of case, ed. by Andrej Malchukov and Andrew Spencer, 219-230. Oxford: Oxford University Press.

Haspelmath, Martin. 2003. The geometry of grammatical meaning: Semantic maps and cross-linguistic comparison. The new psychology of language, ed. by Michael Tomasello, 
vol. 2, 211-243. Mahwah, NJ: Erlbaum.

Malchukov, Andrej L. 2010. Analyzing semantic maps: A multifactorial approach. Linguistic Discovery, this issue.

Narrog, Heiko. 2010. A diachronic dimension in maps of case functions. Linguistic Discovery, this issue.

van der Auwera, Johan 2008. In defense of classical semantic maps. Theoretical Linguistics 34/1.39-46.

Wälchli, Bernhard. 2010. Similarity semantics and building probabilistic semantic maps from parallel texts. Linguistic Discovery, this issue.

Author's contact information:

Heiko Narrog

Graduate School of Information Sciences

Tohoku University

Kawauchi 41

Aoba-ku

Sendai-shi, 980-8576

Japan

narrog@gmail.com 